"Mircea cel Batran" Naval Academy Scientific Bulletin, Volume XIX - 2016 - Issue 2

The journal is indexed in: PROQUEST / DOAJ / Crossref / EBSCOhost / INDEX COPERNICUS / DRJI / OAJI I

JOURNAL INDEX I I2OR / SCIENCE LIBRARY INDEX / Google Scholar / Academic Keys/ ROAD Open Access I

Academic Resources / Scientific Indexing Services / SCIPIO / JIFACTOR

\title{
SHIP'S GENERAL DYNAMICS PRIORITY RESEARCH DIRECTION IN THE XXI CENTURY. CFD APPLICATIONS
}

\author{
Iordan NOVAC ${ }^{1}$ \\ Catalin FAITAR ${ }^{2}$ \\ 1 Associate Professor Eng., Constanta Maritime University \\ 2 Eng., Constanta Maritime University
}

Abstract:To make a robust hull shape the designer must have extensive knowledge in how the global parameters affect the performance. CFD(Computational Fluid Dynamics) could be used to gain more knowledge in how to make a robust hull shape. CFD applications could be used to gain more knowledge in how to make a rugged hull. CFD applications have been increasingly used in designing more ships, more precisely how can it be applied in conceptual stages of ship design. Constraints of time and computational development make a selection of chosen access more complicated. As a standard option on ships optimization, they were used simulations like hybrid computing schemesand meta-modelling.

Keywords: CFD, hull, simulation, WP

\section{NewCFD applications}

SEAWAY is a Strip Theory Program to calculate wave-induced loads on and motions of mono-hulls and barges in deep to very shallow water.

Like hydrodynamic configuration and computation we have:Wamit, Shipx(VERES), Octopus (SEAWAY) etc.

This kind of programe computes:

- Frequency-dependent added mass and potential damping

- Restoring forces
- Froude-Krylovand diffraction forces (1st-order wave loads)

- Wave drift (2nd-order wave loads)

- Viscous roll damping (Ikeda damping etc.)

- Trim optimization

- Hull optimization

- Appendage improvement

- Resistance prediction.

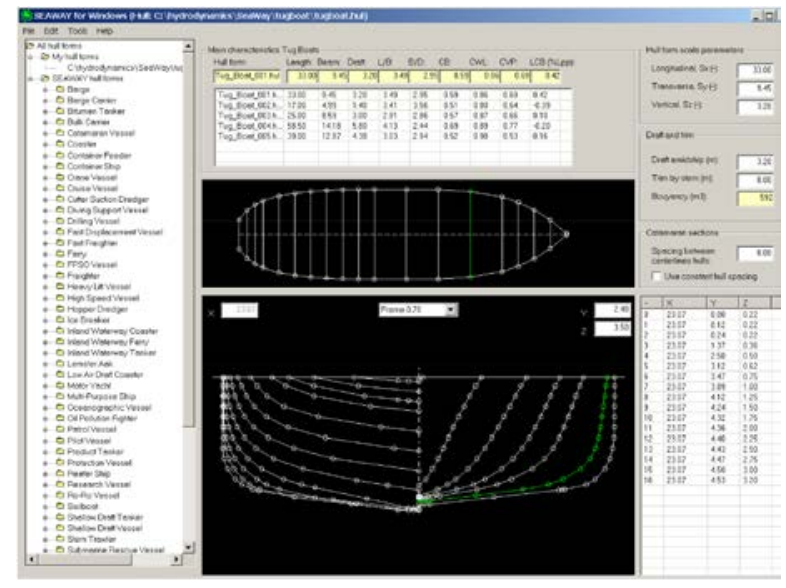

Figure 1. SEAWAY window program

2. Hydrodynamic aspects for ship operations 2.1. Aims for hydrodynamic aspects Investigating hydrodynamicis a Knowledgebuilding project with user involvement financed by The Research Council of Norway and industrial partners. The project objective is to develop new knowledge and new tools for studies of complex ship-to-ship operations. Project work packages have been designed to improve computational fluid dynamic tools for multiple bodies in close proximity and simulation models for interaction forces and moments. The final work package uses operational experience as an input to studies of future operational guidance tools for ship-to-ship operations

The Knowledge-building project with user involvement is divided in four scientific work packages: 
"Mircea cel Batran" Naval Academy Scientific Bulletin, Volume XIX - 2016 - Issue 2 The journal is indexed in: PROQUEST / DOAJ / Crossref / EBSCOhost / INDEX COPERNICUS / DRJI / OAJI I JOURNAL INDEX I I2OR / SCIENCE LIBRARY INDEX / Google Scholar / Academic Keys/ ROAD Open Access I Academic Resources / Scientific Indexing Services / SCIPIO / JIFACTOR

- Computational Fluid Dynamics

- Experimental Measurements - Visualization Studies

- Mathematical models

- Nautical aspects and guidance system design

\subsection{CFD activities}

Viscous flow around two interacting shipsThe primary task of this work package (WP1) is to calculate the flow field around two bodies very close to each other. In real life, this is a ship-toship operation. The CFD calculations will be done with software capable of modelling turbulence (DNS, LES, U/RANS) in order to take important viscous effects into account.

The main goals are :

- $\quad$ to capture the viscous flow field between two ship hulls at very close distance
- to calculate the flow field close to two ships moored in a varying current

- find flow quantities (velocity, pressure) that can be visualised and compared to experimental results from PIV measurements in WP2.

The detailed viscous flow calculations done in WP1 and experiments done in WP2 are motivated by parallel ongoing CFD activities and the need for understanding and get insight into the complex flow patterns. It will also make it possible to investigate situations never met in real life (accidents, hazards etc). The findings in WP1 and WP2 may result in more physical correct models used in real-time simulators (WP3) for actual ship operations.

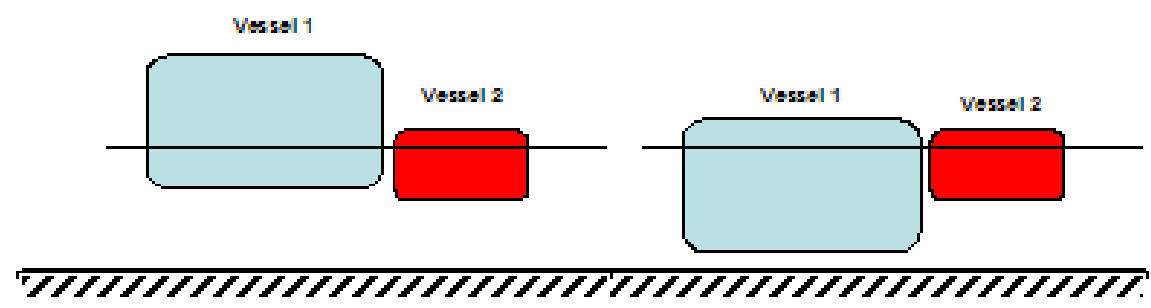

Ballast Condition

Loaded Condition

Figure 2.Two ships in loading condition
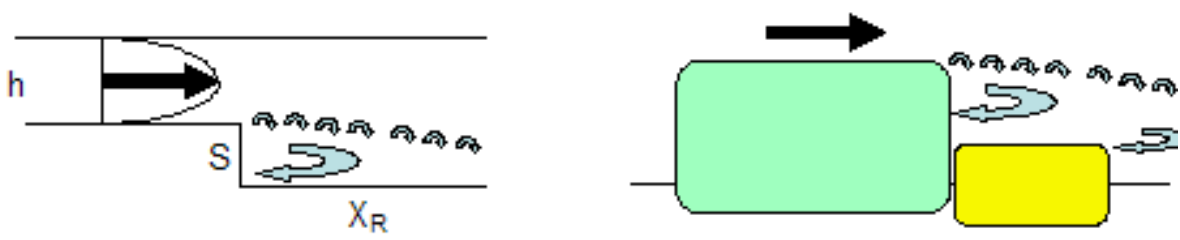

Figura 3.Backward facing step and ship-ship operation (flipped $180 \mathrm{deg}$ )

We will use different existing CFD software, and they will all be capable of simulating viscous (turbulent) flow. Will be used the High Performance Computing resources.
Basic flow studies may include configurations with cross flow on two ships in loading condition, based on experience with backward/forward facing step simulations.

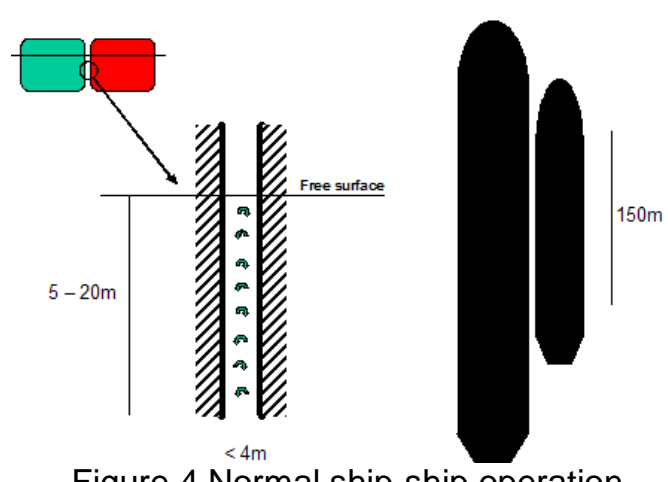

Figure 4.Normal ship-ship operation 
"Mircea cel Batran" Naval Academy Scientific Bulletin, Volume XIX - 2016 - Issue 2

The journal is indexed in: PROQUEST / DOAJ / Crossref / EBSCOhost / INDEX COPERNICUS / DRJI / OAJI I JOURNAL INDEX I I2OR / SCIENCE LIBRARY INDEX / Google Scholar / Academic Keys/ ROAD Open Access I Academic Resources / Scientific Indexing Services / SCIPIO / JIFACTOR

In normal operation, the separation distance and length of the two ships are shown in figure 4.

The viscous fluid flow in between the ships, both in vertical (depth) and longitudinal (along the ship hull) direction will be studied too.

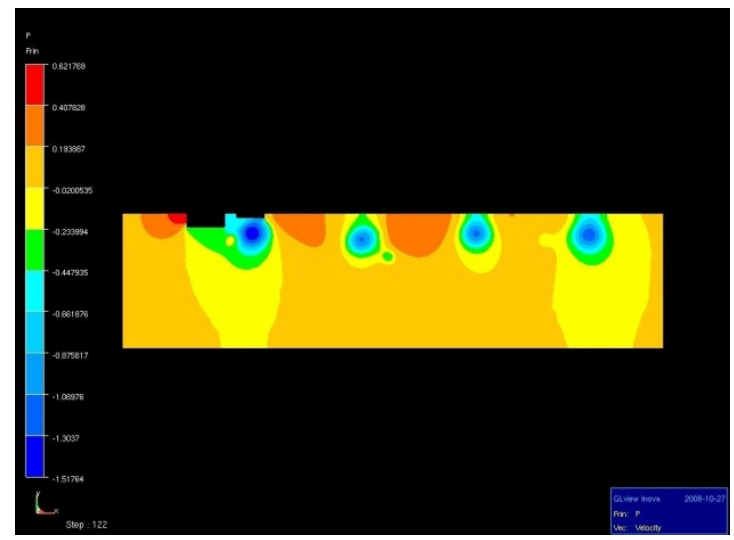

Figure 5.CFD simulations

\subsection{Mathematical models}

This work package will investigate ways of representing interaction forces and moments in fast and real time simulation models. Some existing models are using tables where forces and moments depend on the relative longitudinal and transverse positions of the vessels as found for some standard vessels. The outcome from this project will be interaction forces and moments calculated from the actual ship's geometries, relative positions and speeds. Results from Work Package 1 and Work Package 2 will be used when developing interaction models.

A review of existing interaction models will be completed late 2007. Proposals for new ways of representing interaction forces and moments will be studied in 2008. By end of 2008 subject matter experts will propose how interaction forces and moments shall be represented in the real time simulation model used by project partners. Experience from using this model will be reviewed before the end of the project with the goal of improving the model based on new results from work package 1 and work package 2 and feedback from nautical experts on ship-to-ship type operations.

In earlier work done by students, it was assumed that the growth of force parameters follow a simple power-law. The general form of the equations for force and moment coefficients may then be expressed as:

$C_{X_{0} Y_{N}}=f($ time $) x A x\left[\frac{Y_{C C}}{B}\right]^{\propto Y}\left[\frac{T_{S S}}{T_{\text {SSref }}}\right]^{\alpha T S S}\left[\frac{T_{\text {STBL }}}{T_{\text {STBLref }}}\right]^{\propto T S T B L} x$

where

$$
A=\left\{\begin{array}{c}
1 \text { for } C_{X_{m} Y} \\
\text { moment }- \text { arm for } C_{N}
\end{array}\right.
$$

The coefficients, $\alpha$ has been allocated subscripts suitable for the considered parameter. $T_{S S r e f}$ and $T_{\text {STBLref }}$ are reference draughts for SS and STBL, respectively

3. Fluid loads and motions of damaged ships 3.1. Aims in fluid loads and motions of damaged ship

Further research efforts, headed by the UK MoD, were sparked when HMS Nottingham ran aground tearing a 50m hole from bow to bridge, flooding five compartments and almost causing the ship to sink just off Lord Howe Island in 2002. The figure above shows the stricken HMS Nottingham stuck on rocks (left), Close up of damage once lifted from the water (right) from the BBC news website. Whilst the ship remained intact on the rock, it was unknown what would happen to the structure upon release. A collaboration between MoD, Lloyd's Register, UCL and the University of Southampton has been formed to bring together research efforts in this area, the MoD/Lloyd's Register Centre of Excellence for Marine Structures

\subsection{CFD activities}

A computational damaged ship modelling method is being developed using RANS coupled with rigid body motions. In order to gain confidence in the ability of CFD to predict ship motions and pressure fields for use in a structural solver, the problem is being validated in a number of smaller $x f$ Cằses.

Environment and ship motions wave heights are recorded and compared to experimental results for both regular and irregular wave trains. This is 
"Mircea cel Batran" Naval Academy Scientific Bulletin, Volume XIX - 2016 - Issue 2

The journal is indexed in: PROQUEST / DOAJ / Crossref / EBSCOhost / INDEX COPERNICUS / DRJI / OAJI I JOURNAL INDEX / I2OR / SCIENCE LIBRARY INDEX / Google Scholar / Academic Keys/ ROAD Open Access I Academic Resources / Scientific Indexing Services / SCIPIO / JIFACTOR

to validate CFD capability of creating a section of seaway. Current work includes the superposition of wave components to create freak waves using finite depth first order waves described in the equations. A sample of regular (left) and Irregular (right) wave results are shown below.
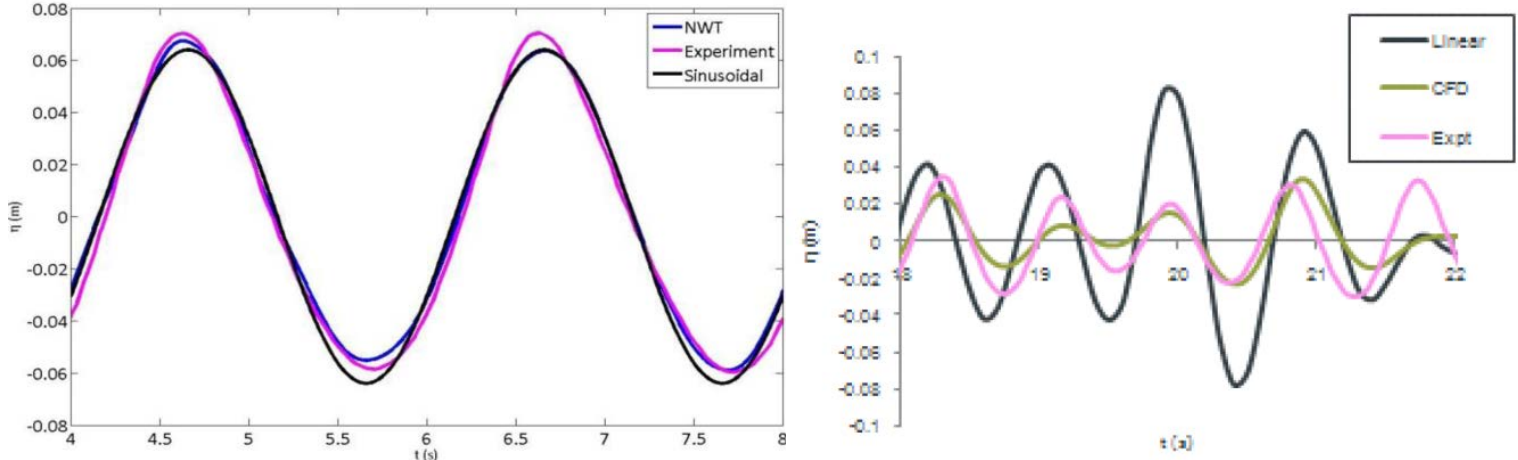

Figure 6. Sample of regular (left) and irregular (right) wave

Rigid body motions is the final component of the validation exercises. The motions are induced by pressures on the hull and the loading and moments of inertia of the ship.
Above diagrams show heave (a) and pitch (b) motions recorded from the simulation of a $5 \mathrm{~m}$ frigate model geometry in waves with forward speed with a Froude number of 0.28 .
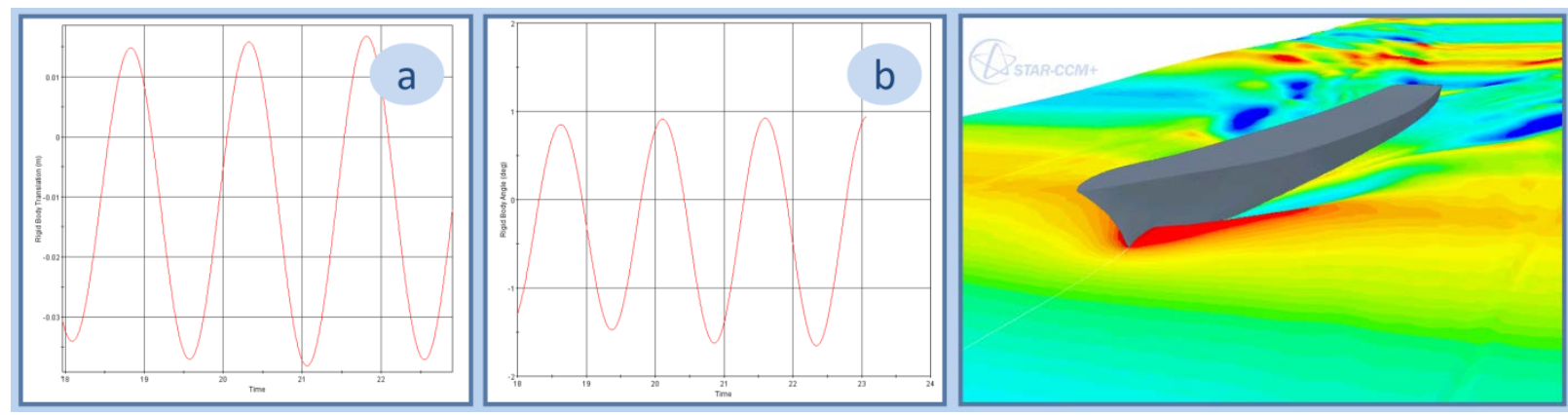

Figure 7. Heave (a) and pitch (b) motions recorded from the simulation of a $5 \mathrm{~m}$ frigate model

Results are shown for the Leander Class Frigate below for regular waves at zero speed.

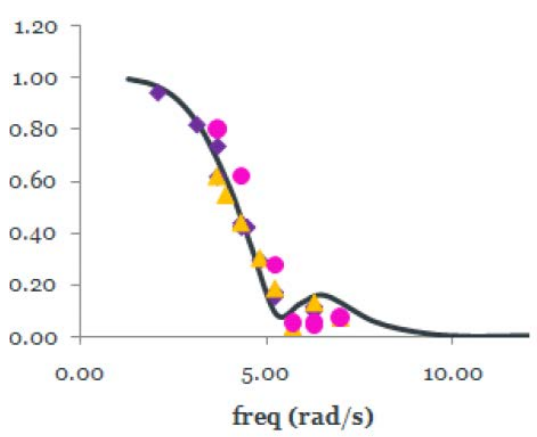

Comparison can be seen between rigid body experiments and rigid body motions and the hydro-elastic response with the segmented model experiments.

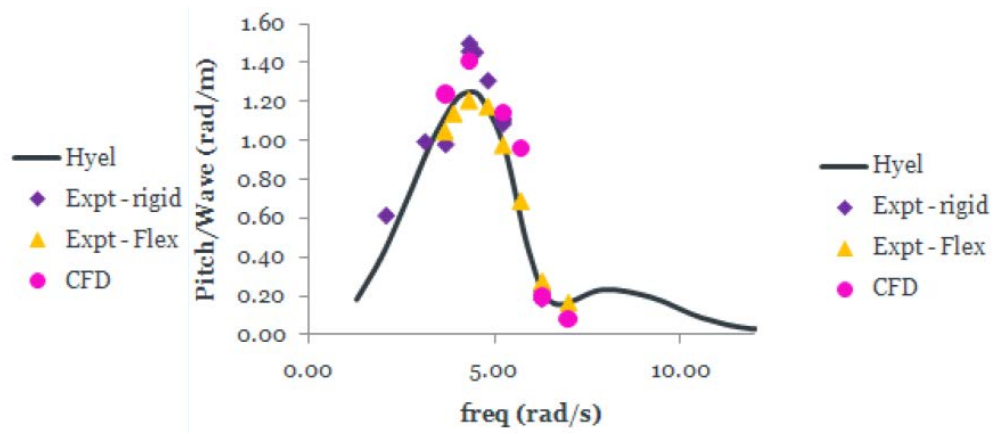

Figure 8. Regular waves at zero speed 
"Mircea cel Batran" Naval Academy Scientific Bulletin, Volume XIX - 2016 - Issue 2 The journal is indexed in: PROQUEST / DOAJ / Crossref / EBSCOhost / INDEX COPERNICUS / DRJI / OAJI I JOURNAL INDEX I I2OR / SCIENCE LIBRARY INDEX / Google Scholar / Academic Keys/ ROAD Open Access I Academic Resources / Scientific Indexing Services / SCIPIO / JIFACTOR

\subsection{Flooding and wave Impact}

2D Dambreak is a classical free surface problem to simulate and lends itself to the validation of wave impact and pressure peak capture.

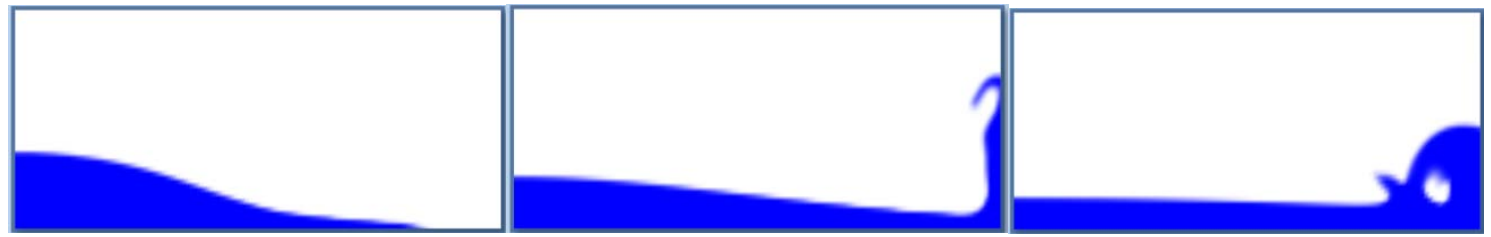

Figure 9. Wave impact and pressure peak capture

Pressure data is recorded and measurements compared to experimental data from the right hand wall $0.16 \mathrm{~m}$ from the floor.
Quantitative comparison is found for pressure everywhere but at the peaks due to the coarse mesh and the 1st order time discretisation scheme that was used in the CFD study.
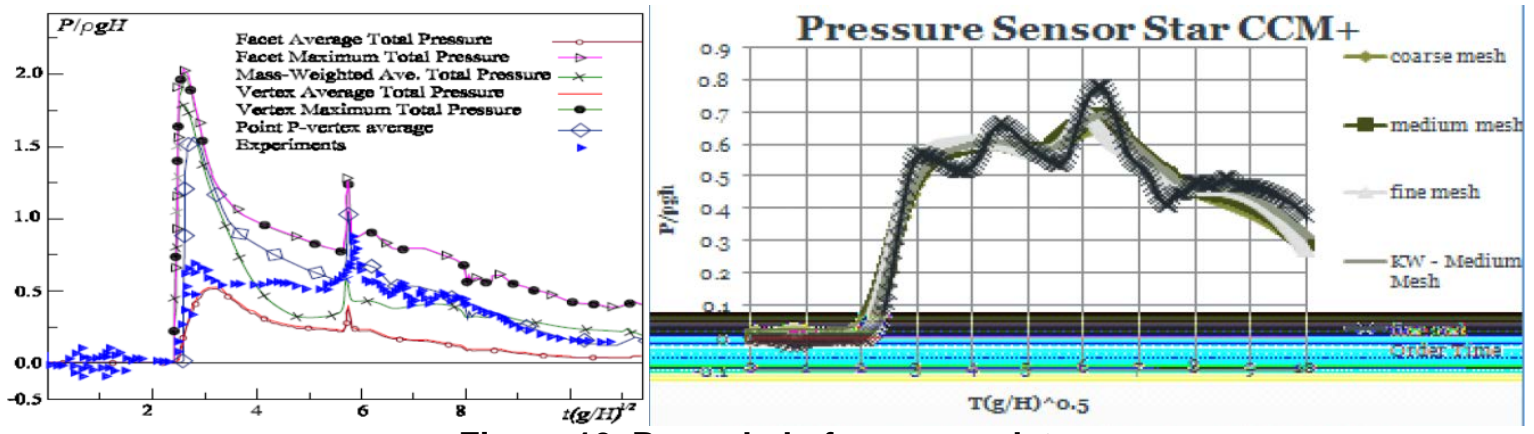

Figure 10. Recorded of pressure data

For flooding simulation volume flow rate through an orifice is generally calculated using a simplified formula which includes correction for viscous effects by use of a discharge coefficient CD.
Typically this value is assumed to be constant, through experiment and CFD this assumption is being tested. Preliminary CFD results are shown below.

Table 1. CFD results

\begin{tabular}{|c|c|c|c|c|}
\hline Damage Area $\left(\mathrm{m}^{2}\right)$ & Shape & Time to flood $(\mathrm{s})$ & Average flow rate $\left(\mathrm{m}^{3} \mathrm{~s}^{1}\right)$ & $\begin{array}{c}\text { Average Discharge } \\
\text { Coefficient }\end{array}$ \\
\hline $5.03 \mathrm{E}-03$ & Circle & 1.51 & 0.006740901 & 0.677 \\
\hline $5.03 \mathrm{E}-03$ & Square & 1.46 & 0.006971754 & 0.700 \\
\hline $5.03 \mathrm{E}-03$ & Rectangle & 1.41 & 0.007218979 & 0.725 \\
\hline $2.83 \mathrm{E}-03$ & Circle & 3.19 & 0.003190834 & 0.570 \\
\hline $2.83 \mathrm{E}-03$ & Square & 3.43 & 0.002967569 & 0.530 \\
\hline $2.83 \mathrm{E}-03$ & Rectangle & 3.35 & 0.003038436 & 0.543 \\
\hline $1.26 \mathrm{E}-03$ & Circle & 7.25 & 0.001403967 & 0.564 \\
\hline $1.26 \mathrm{E}-03$ & Square & 9.04 & 0.001125969 & 0.452 \\
\hline $1.26 \mathrm{E}-03$ & Rectangle & 8.14 & 0.001250462 & 0.502 \\
\hline
\end{tabular}

The snapshots taken below show the formation of the vena contracta and the vortex ring formation. For the larger damage (centre), the vortex formation is inhibited, however for small damage (right) two vortex rings are formed, which result in greater energy dissipation and a lower coefficient of discharge. 
"Mircea cel Batran" Naval Academy Scientific Bulletin, Volume XIX - 2016 - Issue 2 The journal is indexed in: PROQUEST / DOAJ / Crossref / EBSCOhost / INDEX COPERNICUS / DRJI / OAJI I JOURNAL INDEX I I2OR / SCIENCE LIBRARY INDEX / Google Scholar / Academic Keys/ ROAD Open Access I Academic Resources / Scientific Indexing Services / SCIPIO / JIFACTOR

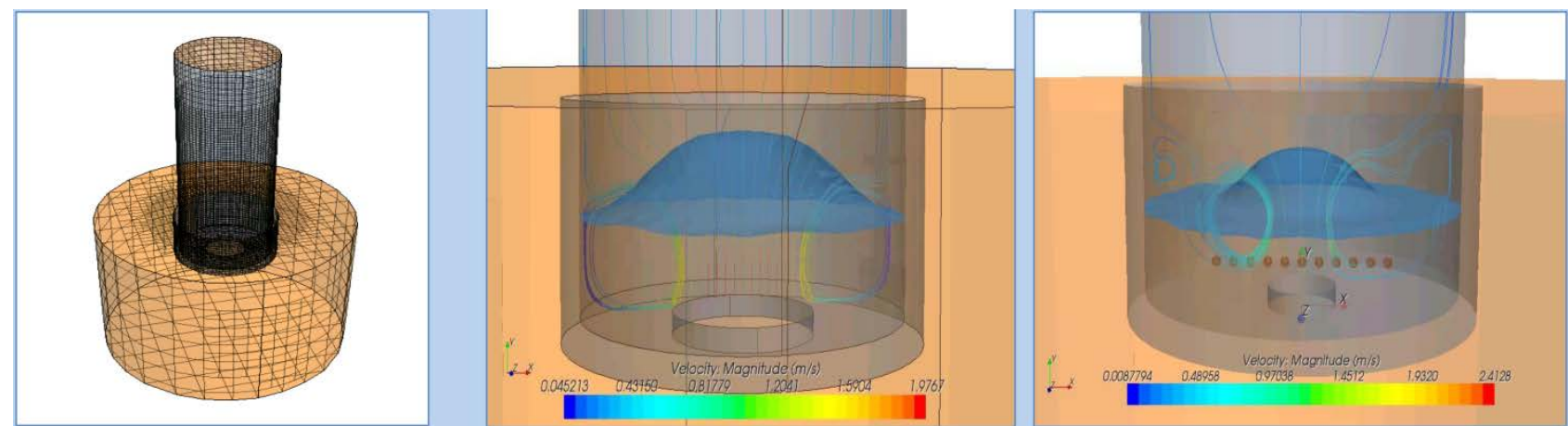

Figure 11. Formation of the vena contracta and the vortex ring formation

4. The influence of surface waves for merchant ships

4.1. Added resistance in rough seas Main causes of added resistance in rough seas are:

- Unfavourable shifts in buoyancy forces causing heaving and pitching. This absorbs energy both from the waves themselves but also from the ships momentum causing speed loss

- Reflection of incident waves at the bow
- Disturbances of the flow around the hull causing boundary layer distortion and poor propeller performance

- Poor power plant performance in unsteady running conditions

- Increased aerodynamic resistance in strong head on winds.

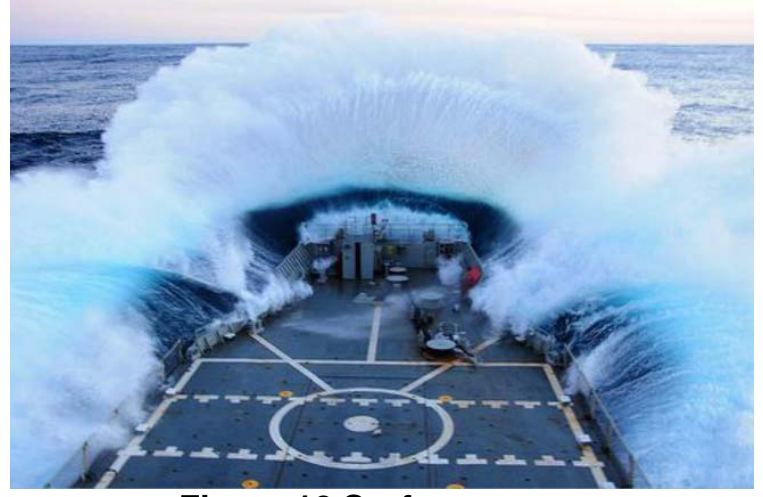

Figure 12.Surface waves

4.2. Aims in influence of surface waves

Main aims in influence of surface waves are:

- To assess the different methods of predicting added resistance and identify strengths and weaknesses

- To Study the influence of the bow shape both above and beneath the waterline on the flow features associated with added resistance

- From this study identify key areas of the forebody where design improvements could be made.
4.3. Methodology in influence of surface waves

The problem can be split up into several individual studies of the different aspects mentioned and the most suitable approach must be chosen for each one. Possible approaches include:

- $\quad$ CFD analysis (e.g. numerical towing tank)

- Custom potential flow approach

- Energy methods

- Towing tank experiments

- $\quad$ Others, yet to conceived. 
"Mircea cel Batran" Naval Academy Scientific Bulletin, Volume XIX - 2016 - Issue 2 The journal is indexed in: PROQUEST / DOAJ / Crossref / EBSCOhost / INDEX COPERNICUS / DRJI / OAJI I JOURNAL INDEX I I2OR / SCIENCE LIBRARY INDEX / Google Scholar / Academic Keys/ ROAD Open Access I Academic Resources / Scientific Indexing Services / SCIPIO / JIFACTOR
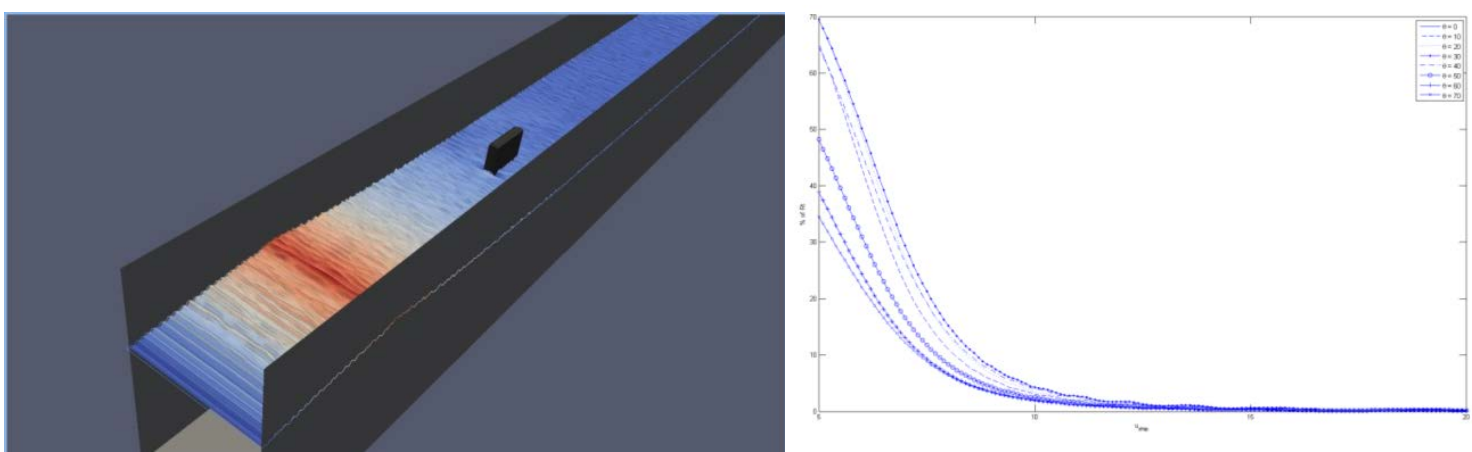

Figure 13. CFD Simulation of object facing a wave (left) and potential flow results linking reflected wave resistance to bow shape and speed (right)

\subsection{Simulations of the multiphase flow around} the KCShullform

- CFD workshops aiming to compare different codes and methodologies for solving pre described ship hydrodynamics problems

- Our combined submission with QinetiQ Ltd contained simulations for the KCS container ship hullform covering

- Wave patern at $F n=0.26$

- Resistance, with sinkage and trim

- And self propulsion at ship point.

\subsection{Modelling}

- Equation: Two-phase Volume of Fluid (VOF) Unsteady Reynolds Averaged Navier-Stokes (URANS) equations

- Turbulence Modeling: Sheer Stress Transport and Reynolds Stress Propeller Model: Axial and tangential body force propeller model.

\section{Numerical Method}

- Discretization: Finite volume method on collocated (nonstaggered) grids

- Advection Scheme: High resolution (bounded second order)

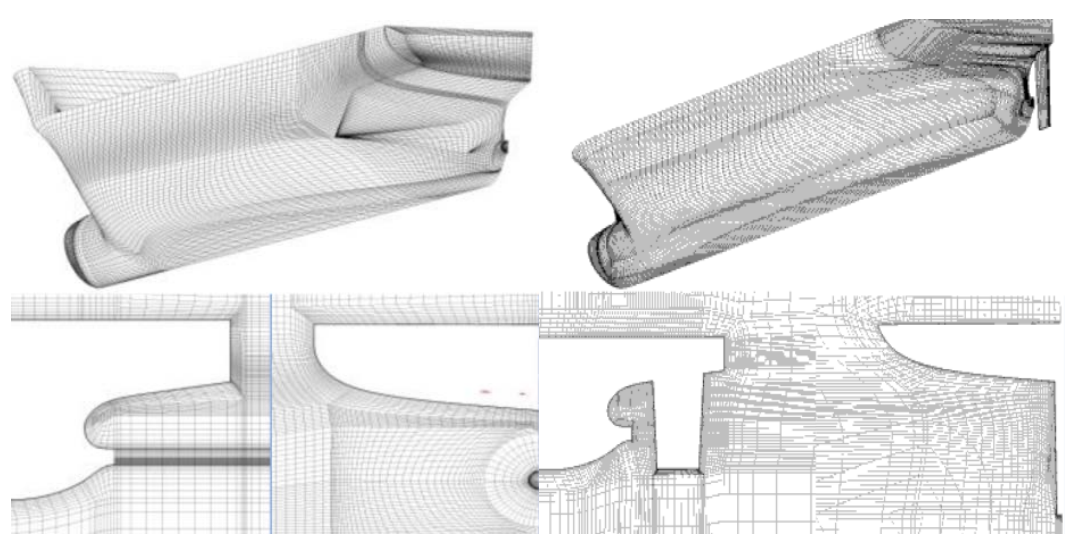

Figure 14. Hull surface mesh and surrounding O-grid structure for Cases 1 and 2 (right) and 3 (left) Note a comparison of the two meshing strategies, Soton and QinetiQ, was made by conducting the case 1 simulations using both meshes (without a rudder).
- Temporal discretization: Second order

- Velocity-pressure coupling: Fully coupled solver

- Mesh movement: Mesh deformation.

Grids, Domains and Boundary Conditions

- Grids: (Case1 and 3 (Southampton)) Systematically refined structured grids $(10,4.5$ and $1.5 \mathrm{M}) \mathrm{y}+=1, \quad$ (Case 2 (QinetiQ)) Structured grids $(680 \mathrm{~K}, 1 \mathrm{M}, 1.7 \mathrm{M}, 3 \mathrm{M}, 5 \mathrm{M}$ and 9M) ) $y+=10$

- Domain: the domain size matches towing tank dimensions in $[Y, Z]$ and extends +-2.0L from the hull in $X$. Half the ship is modelled fro Case 1 and 2 full ship for Case 3

- Boundary Conditions: Hull has a no-slip wall, $\mathrm{X}$-min (upstream) is uniform velocity (U0) inlet, X-max (downstream) and Z-max (top) is an opening with entrainment, Y-max (side) and Z-min (bottom) use free-slip walls, a longitudinal symmetry plane at $Y=0$, is used for cases without the propeller. backward Euler 
"Mircea cel Batran" Naval Academy Scientific Bulletin, Volume XIX - 2016 - Issue 2 The journal is indexed in: PROQUEST / DOAJ / Crossref / EBSCOhost / INDEX COPERNICUS / DRJI / OAJI I JOURNAL INDEX I I2OR / SCIENCE LIBRARY INDEX / Google Scholar / Academic Keys/ ROAD Open Access I Academic Resources / Scientific Indexing Services / SCIPIO / JIFACTOR

\subsection{Results}
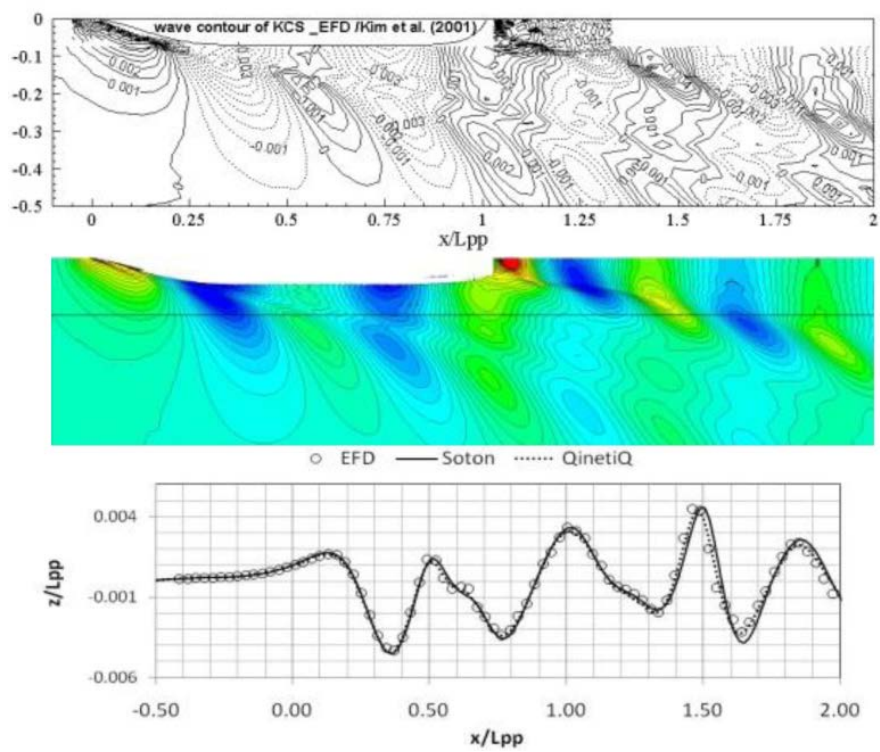

Figure 15.Case 1: Free surface contour plots for EFD (top), Soton CFD (middle) and comparison of a wave cut at $y / L=0.15$ for both Soton and QinetiQ meshes with EFD data (bottom).
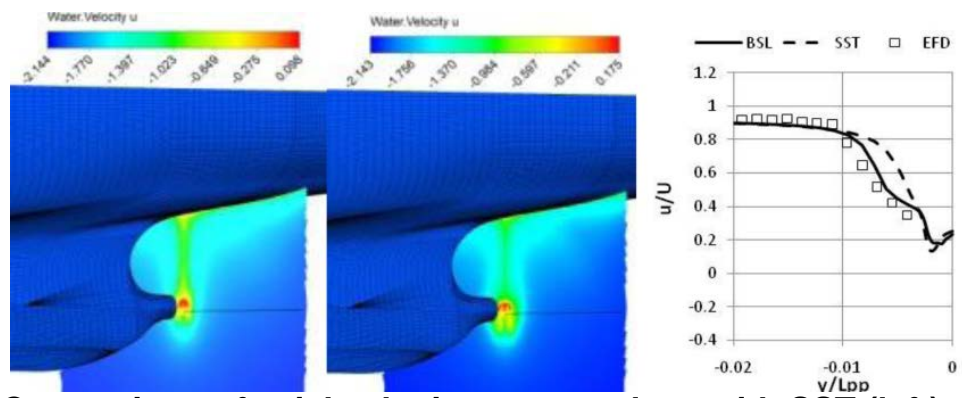

Figure 16. Case 1: Comparison of axial velocity at prop plane with SST (left), BSL (middle) and both plotted against EFD data (right).

The free surface simulations for Case 1 (Figure 16) shows good correlation between the numerical results and the EFD data for both contour plots and wave cuts. The BSL turbulence model was found to be significantly better at capturing theprop plane velocities (Figure 16).

The resistance components for a towed hull free to sink and trim closely agreed with the experimental data (Figure 17).

The body force propeller model in Case 3 simulated the action of the propeller well, but due to the inaccuracies in the nominal wake failed to correctly simulate the experimental data (Figure 17). 
"Mircea cel Batran" Naval Academy Scientific Bulletin, Volume XIX - 2016 - Issue 2 The journal is indexed in: PROQUEST / DOAJ / Crossref / EBSCOhost / INDEX COPERNICUS / DRJI / OAJI I JOURNAL INDEX I I2OR / SCIENCE LIBRARY INDEX / Google Scholar / Academic Keys/ ROAD Open Access I Academic Resources / Scientific Indexing Services / SCIPIO / JIFACTOR
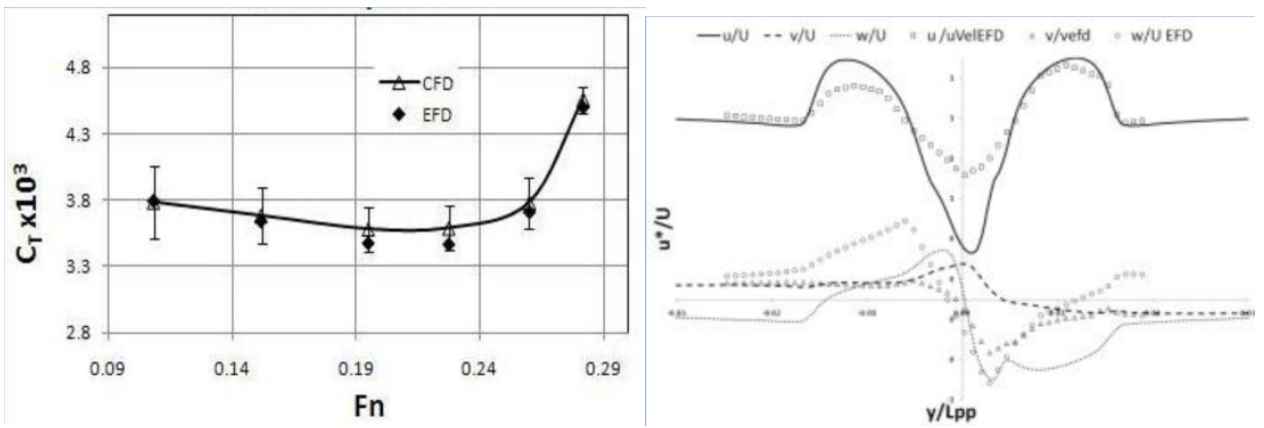

Figure 17. Case 2 Total simulated resistence, plotted with uncertainty, compared to EFD data and Case 3 velocity components at the propeller plane

\section{CONCLUSIONS AND FUTURE WORK}

The component parts require differing levels of grid refinement and modelling approaches, the challenge will be to bring these parts together into a single simulation that gives a stable and accurate solution.

There are many different ways in which a ship can be damaged which bring about different flooding behaviour. Many cases will therefore be conducted to build a response surface for these variables. Therefore the simulations will need to be as computationally efficient as possible.

Future work A detailed investigation into orifice flow will be performed and using the components a full damaged ship model will be built up. For benchmarking and direct simulation of ship motions for any given damage scenario.

\section{BIBLIOGRAPHY}

[1] http://www.ivt.ntnu.no/marinecfd/res-ship2ship.html

[2] Eca, L., Hoekstra, M.,Testing Uncertainty Estimation and Validation Procedures in the Flow Around a Backward Facing Step, Lisbon, 2008

[3] Menter, F.R., Two Equation Eddy Viscosity Turbulence Models for Engineering Application, 1994

[4] Phillips, A.B., Turnock, S.R. and Furlong, M.E.,Evaluation of manoeuvring coefficients of a self-propelled ship using a blade element momentum propeller model coupled to a Reynolds averaged Navier Stokes flow solver,2009

[5] Faltinsen O.M. , Minsaas K.J.,Liapis N.andSkjordal S.O., Prediction of resistance and propulsion of a ship in a seaway, 1980

[6] Denchfield, Wood et al. (2010) Comparisons between CFD predictions and experiments for rogue waveship interactions, 2010

[7] WoodC.,CFD Simulation of Orifice Flow for the Flooding of Damaged Ships, 2010

[8] WoodC.,Numerical Simulation of Compartment Flooding for Damaged Ships, N 2009. 